GU J Sci, Part C, 5(4): 169-177 (2017)

Gazi Üniversitesi
Fen Bilimleri Dergisi
PART C: TASARIM VE TEKNOLOJI
dergipark.gov.tr/http-gujsc-gazi-edu-tr

\title{
Burkulma Mukavemetine Göre Eşit Miktarda Filament Kullanımı İle 3 Boyutlu Baskısı Yapılacak Ankastre Kirişlerin Kesit Geometri Biçimlerinin Performansi
}

\author{
İhsan TOKTAŞ ${ }^{1}$, Murat Tolga ÖZKAN² Hüseyin Alp ÇETINDAĞ $\breve{G}^{3}$ \\ ${ }^{1}$ Ylldırım Beyazıt University, Mechanical Engineering Department 06020 Keçiören, Ankara, Turkey, E-mail: itoktas@ybu.edu.tr \\ ${ }^{2}$ Gazi University Faculty of Technology, Industrial Design Engineering Department, 06500 Ankara, Turkey E-mail: mtozkan06@yahoo.com \\ ${ }^{3}$ Ylldırım Beyazıt University, Institute of Natural and Applied Sciences, Ankara, Turkey, E-mail: h.a.cetindag@outlook.com
}

$\ddot{\mathbf{O} z}$

Makale Bilgisi

Başvuru: $16 / 04 / 2017$

Düzeltme: 22/08/2017

Kabul: 22/11/2017

Anahtar Kelimeler

Filament

Ankastre Kiriş

Burkulma

Optimizasyon

Keywords

Filament

Beam

Buckling

Optimization
Bu çalışmada, aynı kesit alan ve uzunluktaki, eşit miktarlarda filament kullanımı ile 3 boyutlu baskısı yapılacak ankastre kirişler için burkulma mukavemeti yönünden en iyi mekaniksel özelliği sağlayan kesit geometrilerinin belirlenmesi hedeflenmiştir. Bu çalışmada, hızlı modellemede ve plastik parçaların üretiminde sıkça kullanılan filamentin miktarından, üretim zamanından ve harcanan enerjiden bağımsız bir şekilde tasarımlar arasında performansa göre bir sıralama yapılmıştır. Ankastre kirişlerde tasarımların uzunluğu ve uygulanan kuvvetler sabit tutulmuş, içi dolu temel kesit geometri biçimleri (Daire, dikdörtgen, eşkenar üçgen, paralel kenar, elips ve köşeleri yuvarlatılmış dikdörtgen) değiştirilmiştir. Ayrıca, dört farklı filament malzemesi de burkulma mukavemeti yönünden karşılaştırılmıştır. 6 kesit şekline, 101 kesit alanına ve 4 farklı malzemeye bağlı olarak toplam 2424 adet tasarım alternatifi oluşturulmuştur. $\mathrm{Bu}$ tasarım alternatifleri, önce matematiksel olarak modellenmiş, daha sonra sonlu elemanlar yöntemi (FEM) ve regresyon analizi ile test edilmiştir. Tüm modellerin istatiksel analizleri yapılarak karşılaştırılmıştır. Yapılan analizler sonucunda, en düşükten büyüğe doğru, gerilme ve deformasyona uğrayan kesit geometrileri sıralanmıştır. Yapılan çalışma sonucuna göre en güçlü tasarımın PLA dan üretilen üçgen kesitli kirişin olduğu mühendislik hesaplamalarıyla ispat edilmiştir.

\section{Performance Of Cross Sectional Geometries Of Beams According To Buckling Strength Which Are 3d Printed With The Same Amount Of Filament}

\begin{abstract}
Aim of this study is to determine the cross sectional geometries of beams which have better response to buckling with the usage of same amount of filament. These beams have the same cross sectional area and length. Thus, design points were sorted freely without the consideration of the amount of filament, printing time and energy consumption. Length of beams and applied forces were kept constant for each design point, besides that basic cross sectional geometries were changed for each design series. These geometries were selected as, circle, rectangle, equilateral triangle, rhombus (diamond), ellipse and rounded rectangle. Moreover four different printing material were taken into consideration for comparison according to buckling. Depending on 6 different cross sectional shape, 101 cross sectional area and 4 material, totally 2424 design alternatives were built. Firstly, mathematical model of these designs were constructed, then they were tested by using finite element method (FEM) and regression analysis. All model branches were compared to each other with the statistical analysis. As a result of all analyses, design alternatives were sorted according to mechanical strength. According to the result of the study, the strongest design proved by engineering calculations that the triangular section beam produced from PLA.
\end{abstract}




\section{GÍRIŞ (INTRODUCTION)}

Kesit şekli ve malzeme cinsi, üretilecek ürünün gerilme ve gerinim değerlerini etkilemektedir. Bu yüzden kullanılan malzeme miktarına bağlı kalmadan kesit geometrisine göre bir dayanıklılık sıralamasının yapılması gerekmektedir. Literatürde farklı kesit tiplerine ve farklı yüklemeler altındaki malzeme davranışları ile ilgili yapılmış çalışmalar mevcut olmakla birlikte, kesit geometrisi ve eşit miktarda malzeme kullanımına göre bir dayanıklılık sıralaması yapılmamıştır [1-4]. Bu çalışmanın özgünlügü eşit miktarda malzeme kullanarak, zorlanma şiddetine bağlı olarak burkulma değerlerine dayalı malzeme cinsine göre kesit siralaması yapılmasidır.

Günümüzde 3B baskı ve yazıcılar, özellikle ağır sanayiler dışındaki ofislerimizde RP'ye (Rapid Prototype) kolay bir yol desteklemekte ve bize farklı malzeme türüne izin vermektedir. Mücevher, ayakkabı, endüstriyel tasarım, mimarlık, otomotiv, havacılık, dişçilik ve tıbbi endüstriler gibi birçok farklı alanda bu teknik kullanılmaya başlanmıştır. [5]. En önemli uygulamalardan bir tanesi, tasarım geliştirme ve tıbbi modellerin imalatıdır ve bunun sayesinde cerrahi planlamadan önce sanal ve fiziksel anatomik modellerin üretimi amaçlanmaktadır [6,7]. Katkı imalatı veya 3D baskı, şirketlerin şu ana kadar imkânsız olduğu düşünülen şekillerin üretimine izin vererek ürünler üretme biçiminde devrim meydana getirdi. $\mathrm{Bu}$, malzemelerin yük koşulları altında en iyi performans için gerekli olan kesin konumlara yerleştirilmiş parçaları tasarlamanın avantajını sağlar. Bununla birlikte, bu teknoloji ağırlık-performans perspektifinden faydalanırken, sonlu elemanlar analizi ve performans öngörüleri için ayrıştırılması zor olan oldukça karmaşık şekillere neden olur. Bu zorluk, açık çözümlerin tipik olarak kullanıldığı bileşen arızaları gibi son derece doğrusal olmayan olayları tahmin ederken daha da belirginleşti. Geleneksel olarak, benzer elemanlar için tetrahedral elemanlara kıyasla daha yüksek doğruluk ve daha düşük simülasyon maliyetlerinden ötürü açık altı çözümlerde altı yüzlü elemanlar kullanılır. Dolayısıyla rijitlik ve daha özel olarak mukavemet sayısal tahmini, 3D baskılı parçalar için zorlu bir önerme haline gelir [8,9].Farklı bir çalışmada, dolgu deseni seçiminin ve çeşitli mekanik özelliklerin maliyet ve üretim sürelerinin belirlenmesi için tasarım parametrelerini belirlenmesi hedeflemiştir. Bunun için farklı zorlanmalar için deneysel ve FEA analizleri yapılmışıtır [10].

$\mathrm{Bu}$ çalışma, 3D yazıcı aracılığıyla üretilecek olan kirişlerdeki burkulma regresyon analizi, sonlu elemanlar yöntemi ve analitik çözüm aracılığıyla incelenmiştir. Bu sayede kullanılan malzeme ve harcanan enerjiden bağımsız olarak daha sağlam tasarımlar elde edilmiş olacaktır.

\section{YÖNTEM (METHOD)}

\subsection{Tasarimlarin Hazirlanmasi (Preperation of Design Points)}

Tasarlanan bütün kirişlerin boyu $20 \mathrm{~mm}$ dir ve kesit alanları $3 \mathrm{~mm}^{2}$ den $8 \mathrm{~mm}^{2}$ ye kadar artmaktadır. Kesitlerin mukavemet özelliklerinin kıyaslanması için aynı boyda farklı kesit alanlarında örneklerle çalışmalar yapılmıştır. Boy ve kesit alanlarının küçük aralıklarda seçilmesinin sebebi 3 boyutlu yazılarda üretim aralığının belli aralıklarda olmasıdır. Ucuz ve hızlı deney numuneleri elde edilmesi amacıyla kesit boyları ve kesit alanları küçük değerlerde belirlenmiştir. Kesit alanlarının $0,05 \mathrm{~mm}^{2}$ aralıklarla değişmesiyle toplam 101 kesit alanı elde edilmiştir. Çalışmada yer alan en büyük ve en küçük kesit alanına sahip tasarımlar Şekil 1 de gösterilmiştir.

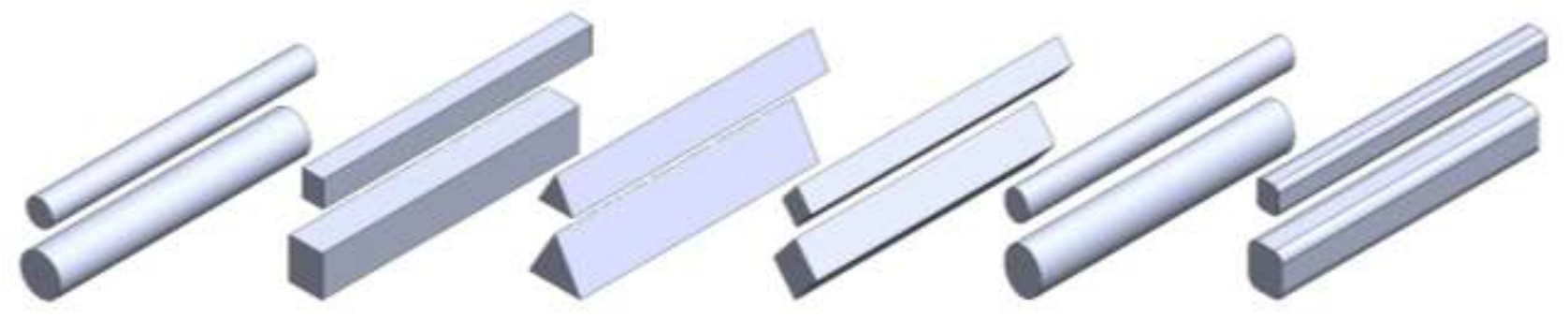

Şekil 1. Soldan sağa doğru sırasıyla; daire, dikdörtgen, eşkenar üçgen, paralelkenar, elips ve yuvarlatılmış dikdörtgen şeklindeki kesitlere sahip tasarımlar. Kesit alanı üstte $3 \mathrm{~mm}^{2}$, altta ise 8 $\mathrm{mm}^{2}$ 'dir. 
Analiz ve hesaplamalarda kıyaslamanın yapılabilmesi için bu şekilleri oluşturan ölçü oranları sabit tutulmuştur. Elde edilen bu oranlar Çizelge 1 de gösterilmiştir.

Çizelge 1. Seçilen kesit geometrileri ve bu şekillere ait ölçüler.

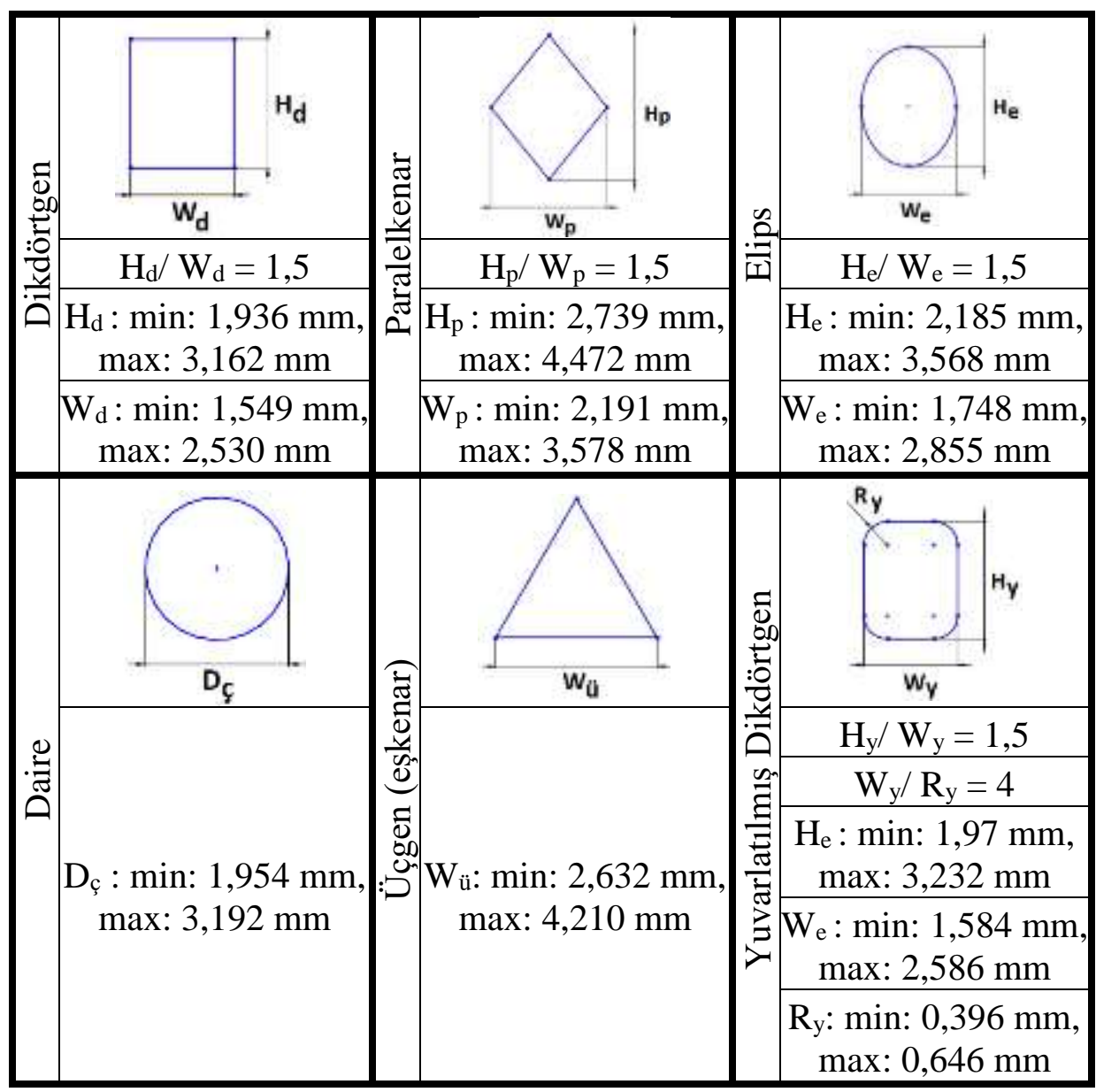

Altı adet kesit geometrisi ve 101 adet kesit alanı kullanılarak elde edilen 606 tasarıma 3D bask1 tekniğinde sıkça kullanılan; ABS (Acrylanitrile Butadiene Styrene), PLA (Polylactic Acid), PETG (Polyethylene terephthalate glycol-modified) ve PC (Polycarbonate) malzemeleri uygulanmıştır. $\mathrm{Bu}$ sayede toplam 2424 adet birbirinden farklı tasarım oluşturulmuştur. Kullanılan bu malzemelerin mekaniksel özellikleri Çizelge 2 de gösterilmiştir.

Çizelge 2. Kullanılan malzemelerin mekanik özellikleri

\begin{tabular}{|c|c|c|c|c|}
\cline { 2 - 5 } \multicolumn{1}{c|}{} & $\begin{array}{c}\text { Elastikiyet } \\
\text { Modülü }\end{array}$ & $\begin{array}{c}\text { Poisson's } \\
\text { Oranı }\end{array}$ & $\begin{array}{c}\text { Maksimum Basma } \\
\text { Mukavemeti }\end{array}$ & Özkütle \\
\hline ABS & $2250 \mathrm{MPa}$ & 0,35 & $49 \mathrm{MPa}$ & $\begin{array}{c}1,05 \\
\mathrm{~g} / \mathrm{cm}^{3}\end{array}$ \\
\hline PLA & $3500 \mathrm{MPa}$ & 0,36 & $93,8 \mathrm{MPa}$ & $\begin{array}{c}1,24 \\
\mathrm{~g} / \mathrm{cm}^{3}\end{array}$ \\
\hline PETG & $2100 \mathrm{MPa}$ & 0,4 & $55 \mathrm{MPa}$ & $\begin{array}{c}1,27 \\
\mathrm{~g} / \mathrm{cm}^{3}\end{array}$ \\
\hline PC & $2344 \mathrm{MPa}$ & 0,37 & $65 \mathrm{MPa}$ & $\begin{array}{c}1,21 \\
\mathrm{~g} / \mathrm{cm}^{3}\end{array}$ \\
\hline
\end{tabular}




\subsection{Analizlerin Yürütülmesi (Conduction of Analyses)}

Oluşturulan bütün tasarımlar aynı koşullar altında incelenmiştir. Kirişler bir uçtan sabit destekle tutturulmuş, öbür uç ise serbest bırakılmıştır. Serbest uçtan eksenel doğrultuda $10 \mathrm{~N}$ büyüklüğünde basma kuvveti uygulanmıştır. Çözümleme için öncelikle analitik yöntem kullanılmış, daha sonra elde edilen sonuçlar sonlu elemanlar yöntemi (F.E.M.) ile karşılaştırılmıştır. Bu iki yöntem arasında yapılan istatiksel analiz yardımıyla en iyi tasarıma ulaşılmıştır.

\subsubsection{Analitik hesaplama (Analytical calculation)}

Kritik kuvvetler kirişlerin narinlik oranlarına (slenderness ratio) bakılarak Johnson formülü veya Euler kiriş formülü kullanılarak hesaplanmalıdır. Bu yüzden bütün tasarımlar için narinlik oranları hesaplanmış, sonuç olarak da bütün kirişlerin Euler kiriş formülü kullanılarak hesaplanması gerektiği görülmüştür. Kritik yük için Euler kiriş formülü Denklem (1)'de, ve Güvenlik Katsayısı Denklem (2)'de verilmiştir [8]

$$
\begin{gathered}
F_{\text {Kritik }}=\frac{C * \pi^{2} * E * I}{L^{2}} \\
\text { G.K. }=\frac{F}{F_{\text {Kritik }}}
\end{gathered}
$$

Burada $F$ kuvveti, $E$ elastikiyet modülünü, $I$ eylemsizlik momentini, $L$ ise kiriş uzunluğunu ifade etmektedir. Bağlama şekline göre değişen " $C$ ” sabiti ise 0,25 'tir.

Kirişler burkulmanın yanı sıra basma şeklinde de zorlanmaktadır. Kirişlerin hangi zorlanmadan daha çok etkilendiğini görmek için basma gerilmesi de incelenmiştir. $\mathrm{Bu}$ incelemede Basma gerilmesini veren Denklem (3)'ten yararlanılmıştır.

$$
\sigma=\frac{F}{A}
$$

Burada $A$ kesit alanını ifade etmektedir. Basma gerilmesi yüzünden ortaya çıkan güvenlik katsayısı da Denklem (2)'den elde edilmiştir.

Basma gerilmesi ve burkulma zorlanması için hesaplanan güvenlik katsayıları sırasıyla Şekil 2 ve Şekil 3'te verilmiştir.

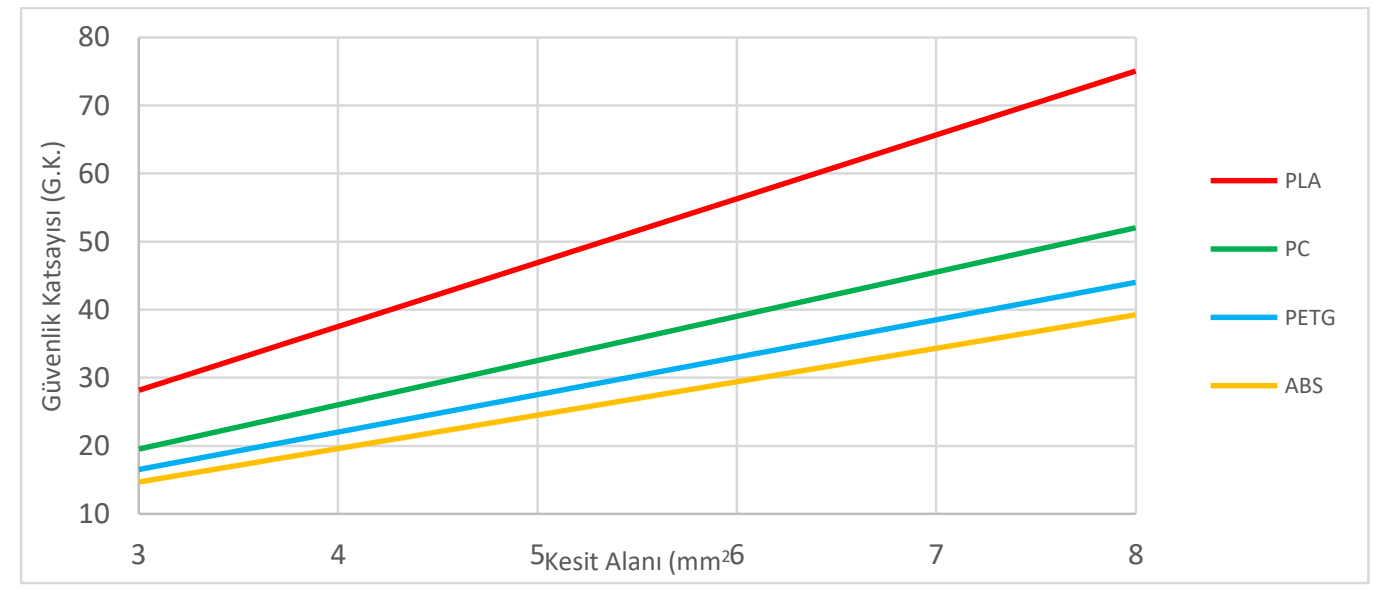

Şekil 2. Analitik olarak hesaplanan tasarımlar için Kesit Alanı ve Basma Mukavemeti Güvenlik Katsayısı grafiği 
Beklendiği üzere güvenlik katsayılar kesit alanıyla doğru orantılı olarak artmıştır. Sadece basma mukavemeti ele alınıldığında aynı kesit alanı için en iyi sonuçlar PLA'dan üretilen tasarımlarda görülmüştür.

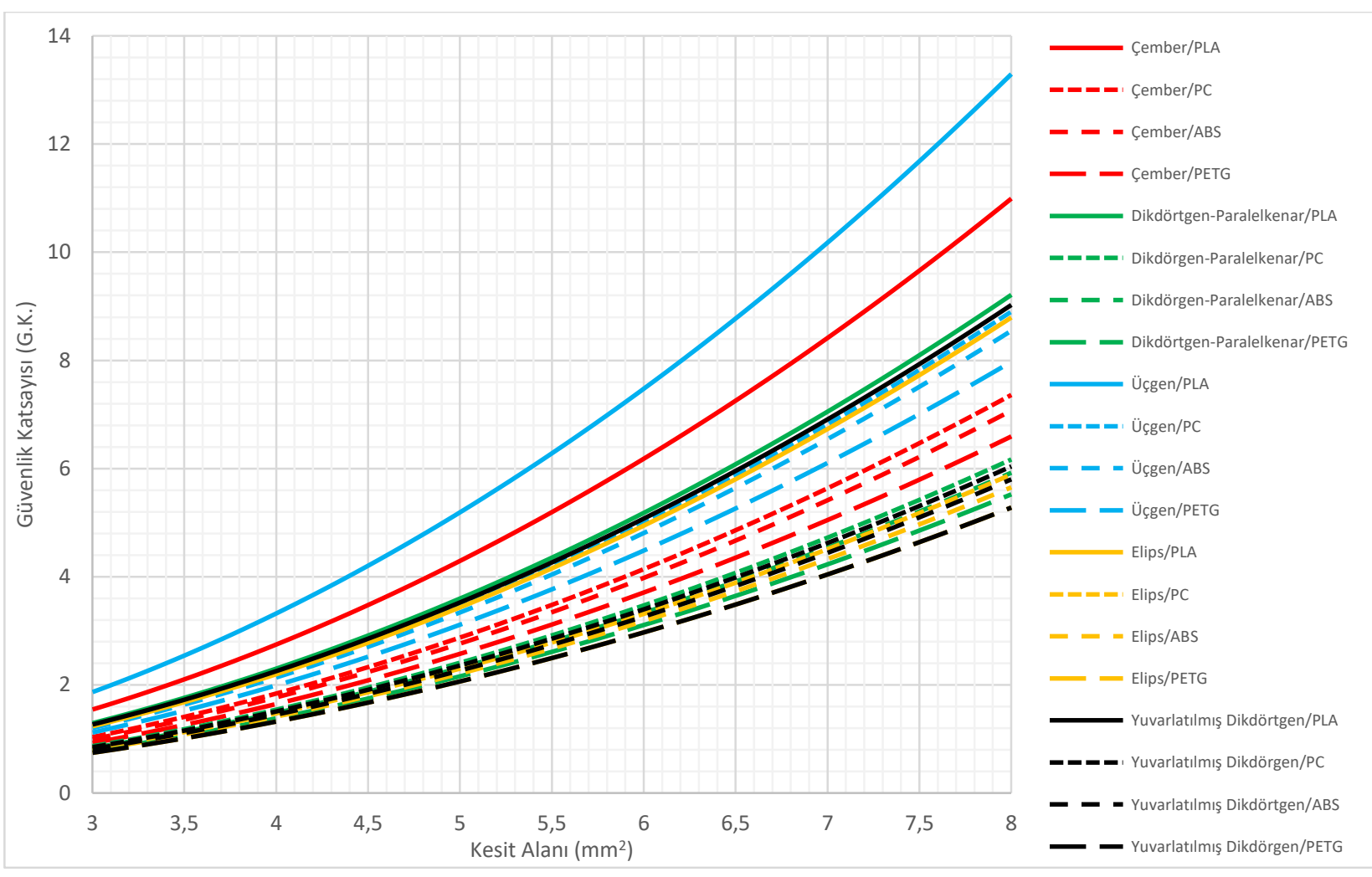

Şekil 3. Analitik olarak hesaplanan tasarımlar için Kesit Alanı ve Burkulma Güvenlik Katsayısı grafiği

Paralelkenar ve Dikdörtgen kesite sahip tasarımlarda aynı değerler elde edilmiş, bu yüzden iki tasarım aynı eğriler kullanılarak ifade edilmiştir. Oluşturulan grafiğe bakıldığında üçgensel kesite sahip kirişlerin diğer kirişlere göre burkulmaya daha mukavemetli olduğu görülmektedir. En düşük mukavemet değerleri ise Elips kesite sahip kirişlerde ortaya çıkmıştır. Elde edilen bu grafik sayesinde istenilen güvenlik katsayısı değerine kesit alanı, kesit geometrisi ve kullanılan malzeme üzerinde değişiklik yapılarak ulaşmak mümkün olmuştur. Düşük kesit alanı değerlerinde tasarımlar arasındaki fark çok net olmasa da kesit alanının büyümesiyle tasarımların birbirlerine göre durumları daha da belirginleşmiştir. En iyi güvenlik katsayısı değerleri bu grafikte de Şekil 2'nin doğruladığı üzere PLA'dan üretilen malzemelerde ortaya çıkmıştır. Bunun yanında iki grafik beraber değerlendirildiğinde basma kuvvetine bağlı güvenlik katsayısı değerleri, burkulmaya bağlı güvenlik katsayısı değerlerinin çok üstündedir. Bu yüzden kirişler üzerinde burkulmanın etkisi basma gerilmesine göre daha fazla ve belirgindir.

\subsubsection{Sonlu elemanlar yöntemi (Finite element method)}

Modellenen 2424 adet kiriş ANSYS programının "Linear Buckling" modülü yardımıyla çözülmüştür. Çözümleme yapılırken oluşturulan "mesh" ve "node" yapılarına dikkat edilmiştir. Analitik hesaplamalar ve sonlu elemanlar yöntemi arasındaki farkı azaltmak için bu yapılarda optimizasyona gidilmiş, tasarımlar arasında aynı teknikler ve aynı büyüklükte "mesh" yapıları kullanılmaya çalışılmıştır.

Tasarımlar bir uçtan "Fixed Support" yardımı ile sabitlenmiş. Öbür uçtan ise 10 N'luk basma kuvveti verilmiştir. Analizler sonucunda kritik kuvvet değerleri ve maksimum yer değiştirmeler elde edilmiştir. En iyi sonuç veren PLA malzemesi kullanılarak tasarlanan kirişler Şekil 4 de gösterilmiştir. 


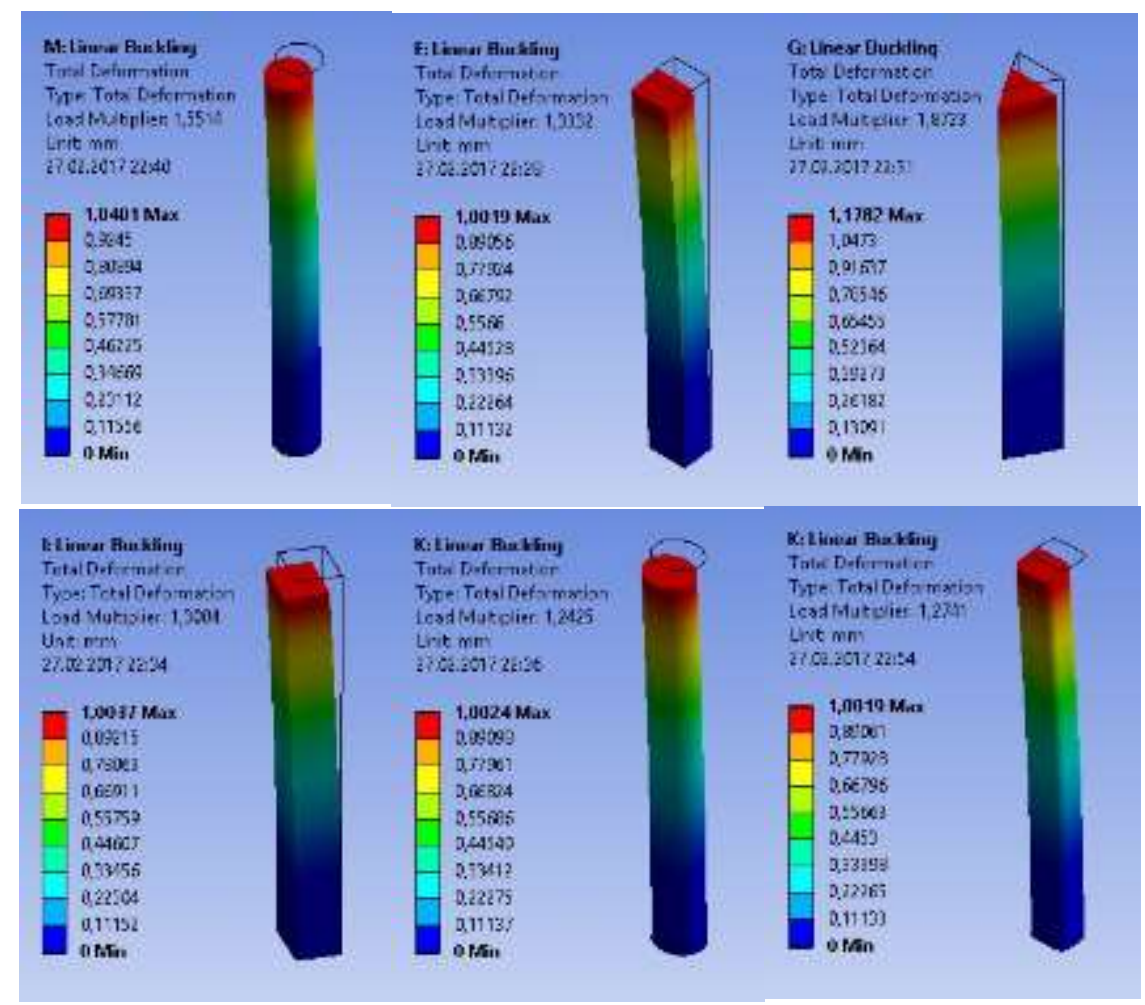

Şekil 4. PLA malzemesine sahip tasarımların burkulma analizleri

Şekil 4 de görüldüğü üzere bütün şekiller eylemsizlik momentinin zayıf olduğu yöne doğru burkulmuştur. Aynı zamanda ortaya çıkan deformasyon da bu şekilde açıkça görülmektedir. Elde edilen sonlu elemanlar analizi beklenen yönde sonuç verse de analitik yöntemle arasındaki fark yüzünden doğruluğunun kontrol edilmesine ihtiyaç duyulmuştur. Bunun için istatiksel analizden ve aşağıdaki formüllerden yararlanılmıştır.

$$
\begin{gathered}
R M S=\left(\frac{1}{p} * \sum_{j}\left|t_{j}-o_{j}\right|^{2}\right)^{1 / 2} \\
R^{2}=1-\left(\frac{\sum_{j}\left(t-c_{j}\right)^{2}}{\sum_{j} t_{j}^{2}}\right) \\
\text { Ort.\%Hata }=\frac{\sum_{j}\left(\frac{t_{j}-o_{j}}{t_{j}} * 100\right)}{p}
\end{gathered}
$$

Bu denklemler kullanılarak deformasyon ve kritik yük değerleri için analitik hesaplama ve sonlu elemanlar yöntemi karşılaştırılmıştır. Bu karşılaştırmada üç adet önemli parametre vardır. $R M S$ değeri " 0 ” a, $R^{2}$ değeri "1" e yakın olmalı ve "Ort \% Hata" değeri ise mümkün olduğunca düşük olmalıdır. Hesaplanan bu parametrelerle birlikte ortaya çıkan maksimum ve minimum sapma değerleri Çizelge 3 te verilmiştir.

Çizelge 3. Kritik yük hesaplamaları için analitik çözüm ve sonlu elemanlar yöntemi arasındaki sapma değerleri

\begin{tabular}{|c|c|c|c|c|}
\hline$R M S$ & $R^{2}$ & Ortalama \% Hata & Maksimum \% Sapma & Minimum \% Sapma \\
\hline 0,154212652 & 0,999359526 & 0,376595524 & 0,708597018 & 0,000135358 \\
\hline
\end{tabular}

Çizelge 3 te görüldüğü üzere iki yöntem arasındaki sapma değerleri çok düşüktür. Özellikle de Ortalama $\%$ Hata ve $\mathrm{R}^{2}$ değerleri yapılan sonlu elemanlar yönteminin doğruluğunu göstermektedir. 


\subsubsection{Regresyon analizi (Regression analysis)}

Yapılan hesaplamalar sonucunda elde edilen veriler regresyon analizi ile tekrar işlenmiştir. Bu sayede analitik hesaplaması zor, sonlu elemanlar yöntemiyle analizi ise uzun süren burkulma fenomeninde her kesit şekli için kritik kuvvetin kesit alanına bağlı denklemleri elde edilmiştir. Yapılan ikinci dereceden regresyon analizlerinde güvenilirlik seviyesi $\% 95$ olarak seçilmiştir. Her malzeme ve kesit şekli için olacak şekilde toplam 24 analiz yapılmıştır. Dairesel kesite sahip kiriş için yapılan regresyon analizi örnek olarak Şekil 5'te verilmiştir.

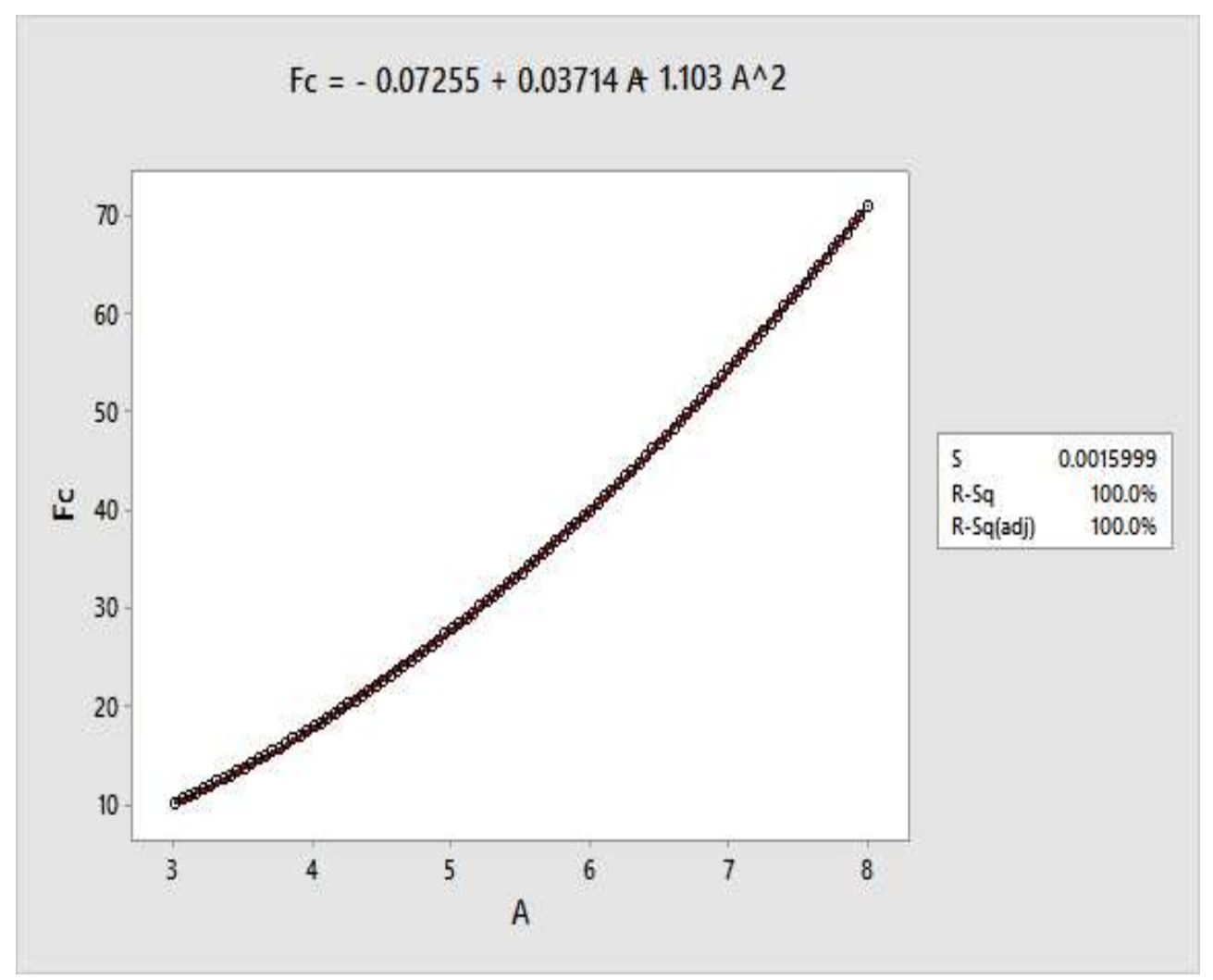

Şekil 5. Dairesel alana sahip kiriş için yapılan regresyon analizi

Elde edilen bu grafikte kırmızı çizgi elde edilen ikinci dereceden regresyon eğrisini, siyah daireler ise analize sokulan değerleri göstermektedir. Burada yapılan analizin yüksek kesinliğe sahip olduğu görülmektedir. Yapılan regresyon analiziyle elde edilen denklemler ise Çizelge 4 te verilmiştir.

Çizelge 4. Regresyon analizinden elde edilen Kesit Alanı-Kritik Kuvvet denklemleri $(F c=k r i t i k$ kuvvet, $A$ =kesit alani)

\begin{tabular}{|c|c|c|c|c|}
\hline & $\mathrm{ABS}$ & PLA & PETG & $\mathrm{PC}$ \\
\hline Daire & $\begin{array}{c}\mathrm{Fc}=0,07255+ \\
0,03714 \mathrm{~A}+1,103 \mathrm{~A}^{2}\end{array}$ & $\begin{array}{c}F c=-0,1090+ \\
0,05605 \mathrm{~A}+1,716 \mathrm{~A}^{2}\end{array}$ & $\begin{array}{c}\mathrm{Fc}=-0,05746+ \\
0,02651 \mathrm{~A}+1,033 \mathrm{~A}^{2}\end{array}$ & $\begin{array}{c}F c=-0,06737+ \\
0,03295 \mathrm{~A}+1,151 \mathrm{~A}^{2}\end{array}$ \\
\hline Dikdörtgen & $\begin{array}{c}F c=-0,04335+ \\
0,02093 \mathrm{~A}+0,9261 \mathrm{~A}^{2}\end{array}$ & $\begin{array}{c}F c=-0,01370- \\
0,02499 A+1,444 A^{2}\end{array}$ & $\begin{array}{c}\mathrm{Fc}=-0,02498+ \\
0,009395 \mathrm{~A}+0,8682 \\
\mathrm{~A}^{2}\end{array}$ & $\begin{array}{c}F c=-0,03530+ \\
0,01557 \mathrm{~A}+0,9666 \mathrm{~A}^{2}\end{array}$ \\
\hline Üçgen & $\begin{array}{c}F c=-0,2119+ \\
0,1198 \mathrm{~A}+1,319 \mathrm{~A}^{2}\end{array}$ & $\begin{array}{c}F c=-0,3265+ \\
0,1844 \mathrm{~A}+2,054 \mathrm{~A}^{2}\end{array}$ & $\begin{array}{c}F c=-0,1860+ \\
0,1034 \mathrm{~A}+1,235 \mathrm{~A}^{2}\end{array}$ & $\begin{array}{c}F c=-0,2184+ \\
0,1225 \mathrm{~A}+1,376 \mathrm{~A}^{2}\end{array}$ \\
\hline Paralelkenar & $\begin{array}{c}\mathrm{Fc}=-0,05396+ \\
0,02762 \mathrm{~A}+0,9250 \mathrm{~A}^{2}\end{array}$ & $\begin{array}{c}F c=-0,07994+ \\
0,04035 \mathrm{~A}+1,440 \mathrm{~A}^{2}\end{array}$ & $\begin{array}{c}F c=-0,03462+ \\
0,01521 \mathrm{~A}+0,8671 \mathrm{~A}^{2}\end{array}$ & $\begin{array}{c}F c=-0,04665+ \\
0,02222 \mathrm{~A}+0,9654 \mathrm{~A}^{2}\end{array}$ \\
\hline Elips & $\begin{array}{c}F c=-0,02621+ \\
0,01054 \mathrm{~A}+0,8864 \mathrm{~A}^{2}\end{array}$ & $\begin{array}{c}\mathrm{Fc}=-0,03146+ \\
0,01147 \mathrm{~A}+1,380 \mathrm{~A}^{2}\end{array}$ & $\begin{array}{c}\mathrm{Fc}=-0,008611- \\
0,000166 \mathrm{~A}+ \\
0,8307 \mathrm{~A}^{2}\end{array}$ & $\begin{array}{c}F c=-0,02138+ \\
0,006775 \mathrm{~A}+0,9248 \mathrm{~A}^{2}\end{array}$ \\
\hline $\begin{array}{l}\text { Yuvarlatılmış } \\
\text { Dikdörtgen }\end{array}$ & $\begin{array}{c}F c=-0,03379+ \\
0,01526 \mathrm{~A}+0,9082 \mathrm{~A}^{2}\end{array}$ & $\begin{array}{c}F c=-0,03737+ \\
0,01612 \mathrm{~A}+1,414 \mathrm{~A}^{2}\end{array}$ & $\begin{array}{c}\mathrm{Fc}=-0,01559+ \\
0,003582 \mathrm{~A}+ \\
0,8512 \mathrm{~A}^{2}\end{array}$ & $\begin{array}{c}F c=-0,03171+ \\
0,01303 \mathrm{~A}+0,9474 \mathrm{~A}^{2}\end{array}$ \\
\hline
\end{tabular}




\section{SONUÇ (CONCLUSION)}

Tasarlanan kirişler hem analitik olarak çözümlenmiş hem de sonlu elemanlar yöntemi kullanılarak hesaplanmıştır. Bu iki yöntem istatiksel olarak karşılaştırıldığında aradaki farkın ortalama \%0,38 civarında olduğu görülmektedir. Bu sayede yapılan sonlu elemanlar yönteminin doğru olduğu sonucuna varılmıştır.

Malzeme yönünden karşılaştırıldığında en iyi sonucu PLA en kötü sonucu ise PETG'nin verdiği ortaya çıkmıştır. Güvenlik katsayısı yönünden karşılaştırıldığında PLA'nın PETG'ye göre \%39,9 daha mukavemetli olduğu görülmektedir. PLA'nın ABS ve PC'ye göre mukavemeti ise sirasılyla \%35,7 ve \%32,9 daha fazla olarak hesaplanmıştır. Malzeme cinsine göre gruplandırılarak elde edilen en yüksek ve en düşük kritik kuvvet değerleri Şekil 6’te gösterilmiştir.

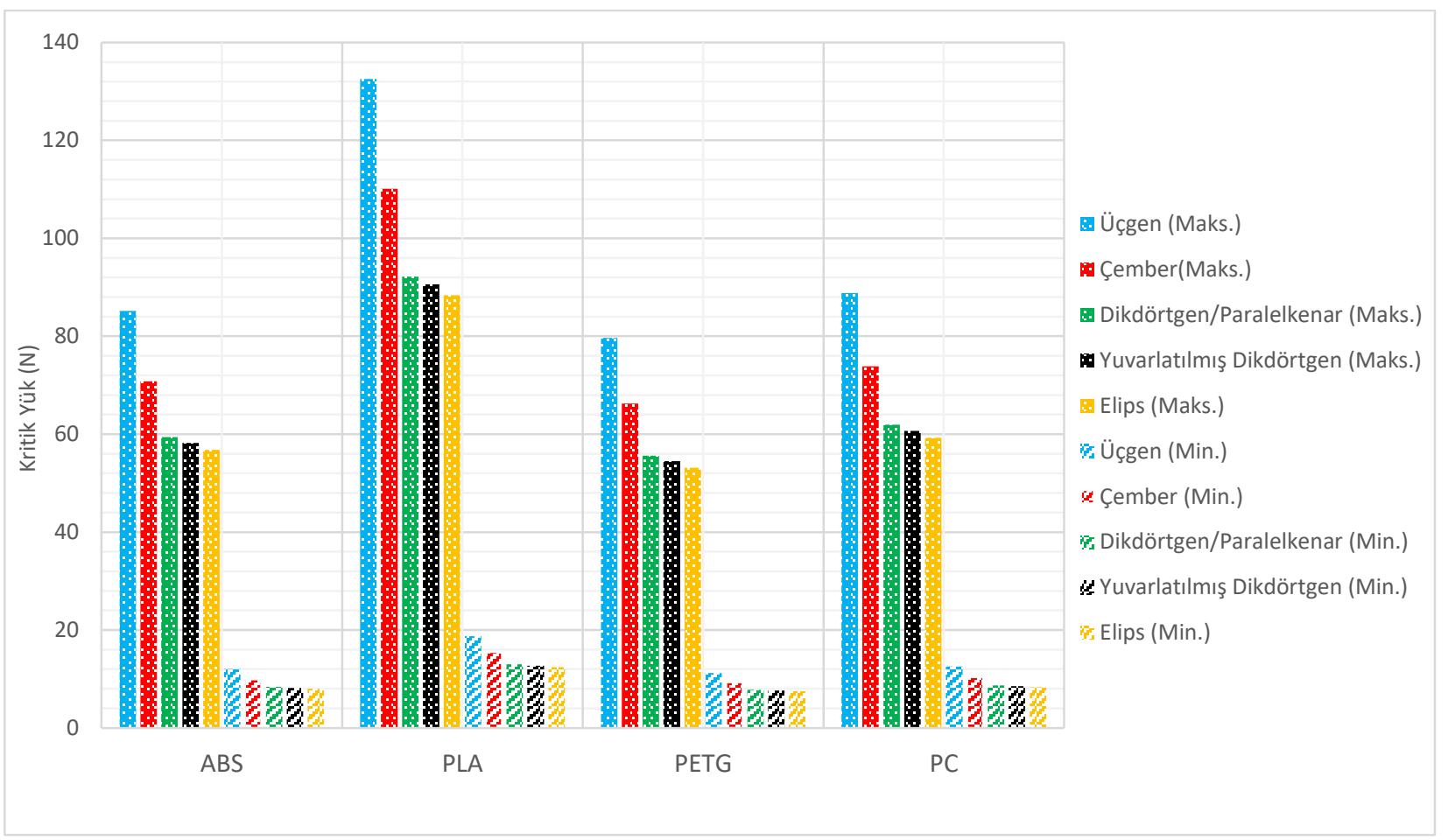

Şekil 6. Kullanılan malzemelere göre ortaya çıkan en büyük ve en küçük kritik kuvvet değerleri

Yukarıdaki grafiğe bakıldığında en güçlü tasarımın PLA dan üretilen üçgen kesitli kirişin olduğu görülmektedir. En kötü tasarım ise PETG'den üretilen Elips kiriş olmuş̧tur. Malzemenin yanında kesit geometrisi de hesaba katıldığı zaman PETG'den üretilen Elips, en iyi mukavemet gösteren PLA'dan üretilen Üçgen kesite göre \%60 daha kötü performans göstermiştir. Elde edilen diğer tasarımların da PLA'dan üretilen üçgen kirişe göre performansları Çizelge 5'te gösterilmiştir. Bu çizelgede aynı özellikleri gösteren dikdörtgen ve paralelkenar kirişler birlikte gösterilmiştir.

Çizelge 5. Tüm tasarımların PLA'dan üretilen Üçgen kirişe göre performansları

\begin{tabular}{|c|c|c|c|c|c|}
\cline { 2 - 6 } \multicolumn{1}{c|}{} & Üçgen & Daire & Dikdörtgen ve Paralelkenar & $\begin{array}{c}\text { Yuvarlatılmış } \\
\text { Dikdörtgen }\end{array}$ & Elips \\
\hline PLA & 0 & $-17,30066569$ & $-30,7179677$ & $-32,13531762$ & $-33,84053255$ \\
\hline PC & $-33,02857143$ & $-44,61507439$ & $-53,60083322$ & $-54,55005271$ & $-55,69205951$ \\
\hline ABS & $-35,71428571$ & $-46,83614223$ & $-55,46155066$ & $-56,37270418$ & $-57,46891378$ \\
\hline PETG & -40 & $-50,38039941$ & $-58,43078062$ & $-59,28119057$ & $-60,30431953$ \\
\hline
\end{tabular}

Sonuç olarak 24 şeklin tamamı da analiz edilmiş, bu analizlere uygun kesit alanı-kritik kuvvet denklemleri elde edilmiştir. Bunun yanı sıra oluşturulan grafiklerden de görüleceği üzere tasarımlar kıyaslanarak modeller arasında mukavemet yönünden sıralama yapılmıştır. $\mathrm{Bu}$ sıralamada performans yönünden \%60'lara varan farklar elde edilmiş, benzer güvenlik katsayısı değerlerinin veya kritik kuvvetlerin farklı malzeme ve kesit şekli kombinasyonları ile elde edilebileceği görülmüştür. 


\section{KAYNAKLAR (REFERENCES)}

[1] Chen, G, Shi, M, and Tyan, T, Cross-Section Optimization for Axial and Bending Crushes Using Dual Phase Steels, SAE Int. J. Mater. Manf. 1(1):537-547, 2009, doi:10.4271/2008-01-1125

[2] Reitinger R, Bletzinger K, Ramm E, Shape optimization of buckling sensitive structures, Computing Systems in Engineering Volume 5, Issue 1, Pages 65-75, 1994

[3] Özakça M, Tayşi N, Kolcu F, Buckling analysis and shape optimization of elastic variable thickness circular and annular plates-I. Finite element formulation, Engineering Structures Volume 25, Issue 2, Pages 181-192 2003

[4] Y.Y. Kim, T.S. Kim, Topology optimization of beam cross sections, International Journal of Solids and Structures 37 477-493, 2000

[5] Biggins P, Hiltz J, Kusterbeck A. Bio-inspried Materials and Sensing Systems. Cambridge: RSC Pub; 2011.

[6] Milovanović J, Trajanović M. Medıcal applications of rapid prototyping. Mechanical Engineering 2007; 5:79-85.

[7] Gibson I. Advanced Manufacturing Technology for Medical Applications: Reverse Engineering. Software Conversion and Rapid Prototyping. West Sussex:John Wiley \& Sons; 2005.

[8] Subhransu Mohapatra, Prasad Dasappa Numerical Prediction of Stiffness and Strength of a Highly Complex Topology Optimized Thermoplastic Part designed for 3D Printing SPE ANTEC ${ }^{\text {TM Indianapolis }}$ 2016.

[9] Lars Krog, A. T. Application of Topology, Sizing and Shape Optimization Methods to Optimal Design of Aircraft Components. Retrieved from Altair product design 2011.

[10] Baich, Liseli, and Guha Manogharan. "Study of infill print parameters on mechanical strength and production cost-time of 3D printed ABS parts." International Solid Freeform Fabrication Symposium, Austin, TX. 2015.

[11] M. Iliescu E. Nuţu, B. Comănescu Applied Finite Element Method Simulation in 3D Printing, International Journal Of Mathematics And Computers In Simulation, Issue 4, Volume 2, 2008, 305-312.

[12] Russell C. Hibbeler, Mechanics Of Materials, Pearson Education Canada 2011.

[13] ANSYS Manual. 